\title{
Percentage of Women Who Missed Taking Oral Contraceptive Pills* Among Women Aged 15-44 Years Who Used Oral Contraceptive Pills and Had Sexual Intercourse, Overall and by Age and Number of Pills Missed - National Survey Of Family Growth, United States, 2013-2015 ${ }^{\dagger}$
}

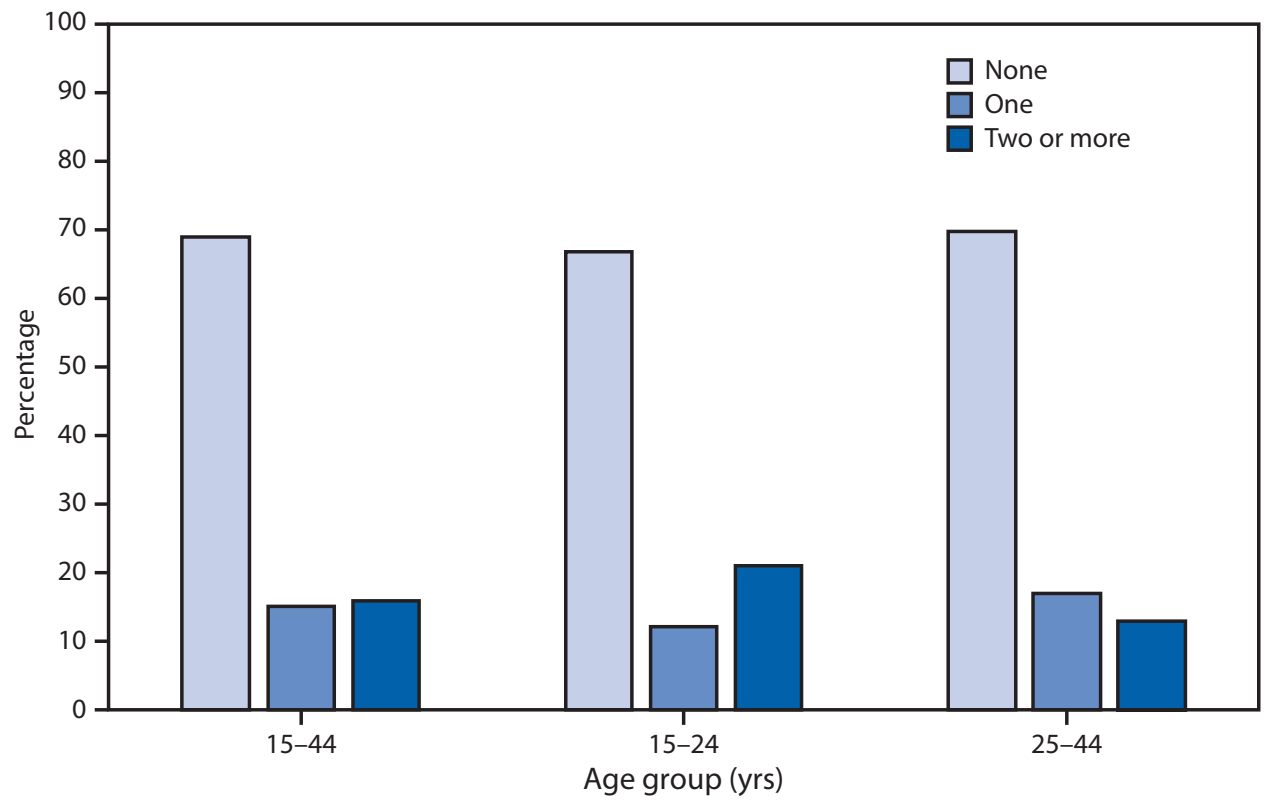

\footnotetext{
* Percentages are based on women who used oral contraceptive pills in the past 4 weeks and had sexual intercourse in the past 12 months, who were asked the question "Still thinking about the past 4 weeks, how many pills that you were supposed to take did you miss? Would you say you never missed a pill, missed only one pill, or missed two or more pills?"

† Estimates are based on interviews of the U.S. household population aged 15-44 years.
}

Among women aged 15-44 years who used oral contraceptive pills in the last 4 weeks and had sexual intercourse in the past 12 months, $69 \%$ of women reported missing no pills, $15 \%$ missed one pill, and $16 \%$ missed two or more pills. Across the two age groups (15-24 years and 25-44 years), similar percentages of women aged 15-24 years reported missing no pills (67\%) compared with women aged $25-44$ years (70\%). Similar percentages of women aged 15-24 years reported missing one pill (12\%) compared with women aged 25-44 years (17\%). A higher percentage of women aged 15-24 years (21\%) reported missing two or more pills compared with women aged $25-44$ years (13\%).

Source: National Survey of Family Growth, 2013-2015. https://www.cdc.gov/nchs/nsfg/index.htm.

Reported by: Kimberly Daniels, PhD, kdaniels1@cdc.gov, 301-458-4511; Joyce Abma, PhD. 